\title{
Evaluation of the Analysis of Classroom Practices of Future Moroccan Teachers
}

\author{
https://doi.org/10.3991/ijep.v11i3.20493 \\ Abdelali Arbia $\left({ }^{\bowtie}\right)$ \\ Sidi Mohamed Ben Abdellah University, Fes, Morocco \\ arbiaabdelali@gmail.com \\ Ihsane Kouchou \\ Cadi Ayyad University, Marrakech, Morocco \\ Fatiha Kaddari, Rida Hajji Hour, Abdelrhani Elachqar \\ Sidi Mohamed Ben Abdellah University, Fes, Morocco
}

\begin{abstract}
The Moroccan education system has undergone several reforms, the most recent of which aims to improve the training of future teachers by integrating the foundations of the professionalization of the teaching profession, which requires the development of professional skills. Indeed, future teachers must learn to take a critical look at their classroom practices, to describe their professional gestures and to analyze their teaching practices in order to evaluate their effectiveness. However, one may ask the following question: is the future teacher trained in such a way as to be able to constantly question his or her classroom practices? To answer this question, we developed an analysis grid of pedagogical practices, which was addressed to primary school trainees at the Regional Center for Education and Training Professions in the city of Fez, Morocco. In order to analyze the pedagogical practices of a future teacher in full action by his peers, this analysis is made from the viewing of a video capsule. The processing of the data collected from the grid revealed that the majority of these future teachers were not able to acquire the capacity to analyze these pedagogical practices in an effective way. The use of the analytical grid was of crucial importance in determining the profile of future teachers able to competently practice their profession.
\end{abstract}

Keywords-Qualifying training, Professionalization, Professional competencies, Analysis grid of teaching practices

\section{Introduction}

The initial training of future teachers in Morocco, considered as a qualifying training, is at the heart of the national education system, it is based on the mastery of pedagogical practices. This qualifying training responds to several challenges that involve all the actors and managers concerned with ensuring good quality training for trainee teachers who must be able to effectively analyze their classroom practices. 
The training provided to future teachers should enable them to develop their professional skills to raise the level of their pedagogical practices so that they can properly carry out the teacher's missions [1]. Indeed, as Visioli, J. \& Petiot, O. pointed out in 2017 [2], the qualifying training of the future teacher is a renewal that must prepare future teachers for a profession in deep and perpetual change and, more generally, for improving the quality of education systems.

To be part of this international movement of innovation in the training of education actors, particularly in Europe, Morocco has reviewed in substance and form the training of teachers, in order to improve the professionalization of the teaching profession. Indeed, until 2011, teacher training has been carried out in three types of institutions: The Teacher Training Center (CFI) whose mission is to train primary school teachers, the Regional Pedagogical Centers (CPR) dedicated to the training of secondary school teachers and the Normal High School (ENS) which trains qualified secondary school teachers. In 2011, the first two institutions were merged into a single institution called the Centre régional des métiers de l'éducation et de la formation (CRMEF) whose main mission is the training and qualification of future teachers in the primary, college and secondary cycles. Access to the CRMEF is open to baccalaureate holders with prerequisites related to communication (ease of expression, ease in speaking in public), related to education (Moroccan education system and its main reforms, main pedagogical approaches) and related to the discipline to be taught. In addition, Morocco is pedagogically committed to the professionalization of training [3]. As a result, training at the CRMEF alternates between theory and practice:

- The theoretical training provided in the CRMEF aims to develop professionalizing skills

- The practical situation (MSP) through training carried out in elementary school, middle schools or high schools qualifying in a professional environment

By incorporating the principle of professionalization, the Moroccan education system has aligned itself with international guidelines for teacher training. The question is therefore: Are the educational actions and activities carried out at CRMEF consistent with this concept?

The professionalization of a teacher requires the development of cognitive, didactic, pedagogical and social skills, and embodies a model that is diametrically opposed to a pedagogical practice based on the implementation of tasks acquired during the qualifying training without innovation or reflexivity [4]. Faced with a changing and complex educational and social context, the teacher must become a reflexive practitioner, capable of adapting to all teaching situations by analyzing his or her own practices and their results [5].

Currently, becoming a teacher means being able to think well about what you do in the classroom, not just mastering the skills to teach and perform prescribed tasks [6].

In summary, a professional teacher is far from being a technician performing predetermined tasks, he must reflect on each of his actions. In this context, the training of future teachers must have among its objectives that of training reflective practitioners and producers and not consumers of existing practices. In addition to disciplinary and didactic skills, the training of future teachers must, on the one hand, prepare them to 
assume their autonomy and responsibilities and, on the other hand, lead them to constantly question their pedagogical practices. Indeed, the future teacher must learn to take a critical and constructive look at his own functioning, he must develop his skills to describe his actions and analyze his approaches and strategies in order to evaluate their effectiveness and to be able to optimize their effects.

In this article, we will answer two major questions which are as follows:

- Would the training model presented to the CRMEF be able to provide practicing teachers with the means and tools to develop and practice appropriate pedagogical practices on a daily basis?

- Is the future teacher trained in such a way as to be able to retrain and to be in perpetual questioning about his or her teaching practices and professional act?

To answer these questions, we developed a teaching practice analysis grid to evaluate the analysis of the future teacher's classroom practices.

The structure of this article is as follows. Section 2 presents a review of the literature on classroom practices of teachers. Materials and methods are defined in Section 3 . The results of the study are presented in Section 4 and discussed in more detail in Section 5 .

\section{$2 \quad$ Literature Review}

As mentioned above, in this research, an attempt was made to revitalize the conference through an interactive pedagogical approach. To do this, the researchers relied on two main criteria that are the basis of effective learning.

We will explain in this section the basic concepts of the research, namely: the professional gesture and the practice of teaching:

- Professional gestures related to all professional actions and gestures aimed at exercising a specific activity

- Teaching practice that refers to the way in which the teacher teaches himself/herself and the way in which he/she carries out a professional teaching activity

\subsection{The notion of professional gestures}

The notion of "professional gesture" was defined in 2009 by Bucheton [7] as being "a set of acts of doing and saying which allows the specific conduct of the class, it is an action to push the other to act". Indeed, a professional gesture is a verbal and / or non-verbal sign addressed to one or more students to arouse their commitment and involve them in an activity. It is part of a school culture shared by students and it reveals an intention that students should understand [8]. In fact, professional gestures, create more or less favorable, more or less opportune, more or less effective interactions in a training situation [9]. According to Bucheton, D. \& Soulé, Y. in 2009 [10], the professional gesture achieves the teacher's action, the updating of his concerns. 
The choice of the term gesture reflects the idea that the action of the teacher is always addressed and inscribed in codes. A gesture is a communication action inscribed in a shared culture. It takes on its meaning in and through the school context.

The teacher's concerns are multiple: how to get the learners to understand, how to make them express themselves, what reactions would be adequate to manage the class. These concerns range from the construction of knowledge to the management of time and space and the general atmosphere of the class and while passing by the need to motivate the students and stimulate their engagement [7]. However, the basis of professional gestures [10], and the matrix of their activity in the classroom [11] can be divided to four points:

1. Steering gestures: Regulate the time, space and flow of tasks to maintain the consistency of the lesson.

2. Supporting gestures: Gestures by which the teacher helps the learner to conclude an activity; this includes the support provided by the teacher to allow students to build their learning.

3. Weaving gestures: Aim to weave the meaning of what is happening and to make links with the before and the after of the lesson. It is the articulation between the different lessons and between the different sequences of the lesson.

4. Atmospheric gestures: Relate to relationships and lead to regulate relationships and maintain a learning environment.

Professional gestures are the basis of professional competencies. For this reason, it is necessary to acquire knowledge about these gestures in order to adjust, improve and analyze classroom practices in an adequate way.

\subsection{Classroom practices}

According to Casalfiore, S. in 2002 [12], teaching practice aims to improve the capacity of the future teacher to transform acquired knowledge into actions. It is defined by Sensevy, G. \& Mercier, A. in 2007 [13], as being everything that a teacher does in the institutions where we teach and where we learn.

The classroom practice analysis is based on three criteria:

- Didactic criterion based on the study of the questions raised by teaching and the acquisition of knowledge in the different school disciplines: management and structuring of knowledge, error management in addition to the teacher's cognitive structure (negotiations of representations, etc.)

- Pedagogical criterion which makes it possible to highlight the importance of the mediating role of the teacher: establishment of learning conditions where the teacher is a mediator between knowledge and the learner and facilitator (choice of teaching situations / learning.)

- Relational criterion, which concerns the relational side between learners, and between learners and their teacher. This is to encourage student engagement and to maintain a certain learning environment: learning climate, management of classroom dynamics and management of interaction with students and between students [14]. 
Professional development is fundamentally based on the professionalization of teaching practices; learning to analyze this practice must be integrated into the training of future teachers. This can be done through: experimentation, observation, reflection, feedback and problems solving [15]. It should also be noted that there is a big gap between classroom practice and what is learned in theory. In fact, first of all, the teacher must not only acquire the theory relating to teaching practice, but must also mobilize a professional gesture among others to get the students to build knowledge and secondly, he must react according to real situations [16].

\subsection{The importance of viewing a video capsule in analyzing teaching practices}

In order to learn to analyze one's own practice, the future teacher must first go beyond the norms of analyzing a practice; this is only possible by learning the practice of others. As a result, group working allows future teachers to collectively acquire adequate knowledge of teaching practices and to co-analyze their classroom practices and offer them opportunities to develop reflexivity and constructive criticism.

Viewing the video capsule is one of the favorable means allowing the analysis of classroom practices, indeed viewing videos of the practices of trainees allows future teachers to know what their colleagues are doing in similar difficult situations teaching or even similar to their circumstances [17]. This type of video offers future teachers an opportunity to improve their classroom practices that engage them in comparative and critical reflections. Thus, viewing a video capsule in teaching practices has several advantages:

- Each future teacher has his own learning level and can view the video capsule as many times as necessary to assimilate certain concepts that he has not understood.

- The video capsule is one of the easily exploited resources in unlimited ways. It has a certain attractiveness which could involve the future teacher in his learning, making him less passive [18].

- Find solutions and initiatives that could ensure the continuity of teaching and learning, especially in the context of the current health crisis linked to the emergence of a new form of coronavirus (COVID-19), in which distance education has played a very important role [19].

\subsection{Classroom practices analysis grid}

Generally, a reliable analysis of classroom practices is carried out using grids developed according to the needs of the trainee's activity and in such a way that they focus on the aspects that the trainer or researcher wishes to highlight. To develop the grid used in this research, we drew on: 
- Mili's, A. researches in 2014 [20] which consisted of a modeling grid for the levels of appropriation of teaching practices. According to Mili, A. this grid allows teachers to analyze their practices and develop them to improve their profession.

- Researches by Bocquillon, M., Derobertmasure, A. \& Dehon, A. in 2017 [21] developed an observation grid called "Mirror of Professional Gestures" (MGP). This grid allows the future teacher to focus on important professional gestures to observe and to develop the qualifying training.

- Researches of Morel, F., Bucheton, D., Carayon, B., Faucanié, H., \& Laux, S. in 2015 [8] and the researches carried out by Altet, M. in 2017 [14] are based on the four professional gestures (piloting gestures, supporting gestures, weaving gestures and atmospheric gestures) and researches of Altet are based on the three criteria (criterion didactic, pedagogical criterion and relational criterion).

Therefore, the objective of this study is to perceive the relevance of the qualifying training of future teachers to train professional practitioners, but the question that can be asked is: is this training adequate to qualify professional teachers?

\section{$3 \quad$ Materials and Methods}

\subsection{Purpose of the research}

The experimentation of this research consists in analyzing the pedagogical practices of a trainee in action by future teachers. The analysis is based on the vision of a video capsule filmed in May 2019 in an elementary school as part of the MSP during the weeks devoted to practical training. The objective of the video sequence is to assess the ability of future teachers to analyze and detect a colleague's teaching practices in an appropriate manner.

Viewing the video capsule is one of the appropriate means of analyzing the teaching practices of future teachers.

Thus, on the basis of this video sequence, we have developed a grid for analyzing the classroom practices of the trainee teacher who is the subject of our study. This grid is of paramount importance for a reliable analysis of teaching practices.

\subsection{Sample and data collection}

The grid was administered to a sample of 90 future teachers out of 150 who are all of the promotion, within the Regional Center for Trades of Education and Training (CRMEF) of the city of Fez, during the training year 2018-2019. This sample was chosen in a probabilistic way of simple random type, in fact, the members of our sample are chosen by lot from a listed list of 1 to 150 people.

As can be seen in Table 1, we based this grid on six indicators (closed-ended questions) that represent the essence of the teachers' analysis and that correspond to the three criteria and the four professional actions already mentioned, we note that each 
criterion is operationalized by two indicators and each indicator is studied according to a measurement scale of three levels which are: yes, partially, no.

Table 1. Grid for peer review of an intern's classroom practices

\begin{tabular}{|c|c|c|c|c|c|c|}
\hline \multicolumn{2}{|c|}{ Criteria } & $\begin{array}{l}\text { Indicators } \\
\text { (Questions) }\end{array}$ & $\begin{array}{c}\text { Professional } \\
\text { gestures }\end{array}$ & Yes & Partially & No \\
\hline \multirow{2}{*}{$\begin{array}{l}\text { Didactic } \\
\text { criterion }\end{array}$} & $\begin{array}{l}\text { Related to } \\
\text { educational } \\
\text { content }\end{array}$ & $\begin{array}{l}\text { Q1: Control and rectify learner } \\
\text { errors? }\end{array}$ & Piloting & & & \\
\hline & $\begin{array}{l}\text { Related to } \\
\text { teaching } \\
\text { methods } \\
\end{array}$ & $\begin{array}{l}\text { Q2: Negotiate the different repre- } \\
\text { sentations of learners? }\end{array}$ & Supporting & & & \\
\hline \multirow{2}{*}{\multicolumn{2}{|c|}{ Pedagogical criterion }} & $\begin{array}{l}\text { Q3: To be a mediator between the } \\
\text { learner and the knowledge? }\end{array}$ & Supporting & & & \\
\hline & & $\begin{array}{l}\text { Q4: Start the session with an explo- } \\
\text { ration situation? }\end{array}$ & Weaving & & & \\
\hline \multirow{2}{*}{\multicolumn{2}{|c|}{ Relational criterion }} & $\begin{array}{l}\text { Q5: Manage space and time in a } \\
\text { balanced manner? }\end{array}$ & $\begin{array}{l}\text { Atmosphere (and } \\
\text { Piloting) }\end{array}$ & & & \\
\hline & & $\begin{array}{l}\text { Q6: Manage interaction with stu- } \\
\text { dents and between students? }\end{array}$ & Atmosphere & & & \\
\hline
\end{tabular}

In fact, we have tried to weave links between criteria, professional gestures and indicators (questions), to:

- Indicator 1 (Q1): focused on the power to control and correct learners' errors linked to the didactic criterion in relation to educational content. It should be noted in this regard that the future teacher must have a whole series of precise didactic gestures to control and rectify the learners' errors in order to control the lesson progress in an efficient manner.

- Indicator $2(\mathrm{Q} 2)$ : articulated on the power to negotiate the different representations of learners linked to the didactic criterion in relation to teaching methods. It should be noted in this regard that the negotiation of the different representations of learners involves a multitude of didactic gestures to support the work in progress.

- Indicator $3(\mathrm{Q} 3)$ : concerns the power of being a mediator between the learner and knowledge and linked to the pedagogical criterion. In fact, the mediating role of the teacher plays a too important role in the resolution of cognitive conflicts; it is the support which confirms the interest necessary to support the learner in his learning process.

- Indicator 4 (Q4): which concerns the beginning of the session with an exploration situation linked to the pedagogical criterion. In fact, starting the session with an exploration situation to make the link between the sessions is a weaving gesture; its goal is to weave links between the sessions to give relevance to the session and meaning to the learning targeted.

- Indicator 5 (Q5): concerns the power to manage space and time in a balanced way linked to the relational criterion. We note that the management of time and space in a balanced way is a piloting gesture that is an action that regulates time 
and space in a relevant way, to maintain a good working atmosphere and preserve an effective relational climate.

- Indicator 6 (Q6): which relates to the power to manage interaction with students and between students is linked to the relational criterion. It is pointed out that, maintaining a certain atmosphere requires a multitude of professional actions, in particular by the good management of the interaction with the students and between the students, the teacher is in charge of maintaining order but also a cognitive and relational climate.

This classroom practice analysis grid (see Table 1) is completed by each trainee individually and anonymously. We also told the future teachers questioned that there is no interference with the evaluation process, because evaluation consists of making judgments by giving a mark to evaluate an assignment. On the other hand, the fact of analyzing teaching practices makes it possible to understand these classroom practices, without judging or marking the work.

\subsection{Data analysis}

The data from the grids distributed to the participants are entered and analyzed by Microsoft Excel software. In addition, the results obtained are presented as a percentage in the form of figures, in order to highlight the teaching practices of future teachers.

\section{$4 \quad$ Main Results}

The results obtained were presented in the form of six sections with reference to the indicators/questions of the analysis grid (see Table 1).

\subsection{Step 1: Checking and correcting learner errors}

In the case of question $1(\mathrm{Q} 1)$ which concerns the control and correction of learners' errors (see Figure 1) We note that the results obtained from the grids filled in by the future teachers show that $54.84 \%$ of the future teachers questioned said that the trainee controlled and corrected the errors of the students. Conversely, $38.71 \%$ of the future teachers surveyed said that they had partially controlled and corrected the errors and a minority of future teachers $(6.45 \%)$ opted for the correct answer by saying that they had not controlled and corrected the errors of the learners. 


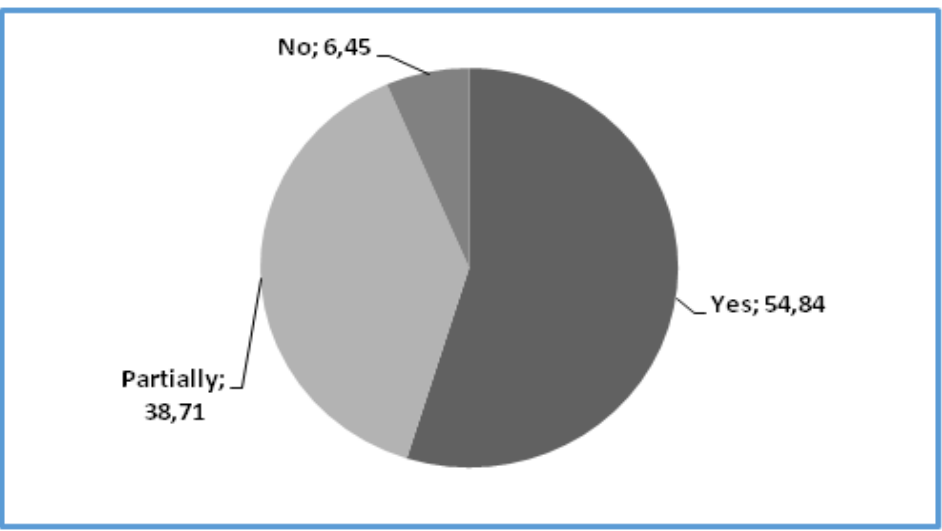

Fig. 1. Percentages of responses regarding the control and correction of learner errors

\subsection{Step 2: Negotiating different learner representations}

The second question $2(\mathrm{Q} 2)$ concerns the negotiation of the different representations of the learners (see Figure 2). We note that $48.39 \%$ of the population surveyed chose that the trainee was not able to negotiate the different representations of the learners. While $22.58 \%$ of the surveyed population stated that they had negotiated the different representations of the learners and $29.03 \%$ stated that they had partially negotiated the different representations of the learners.

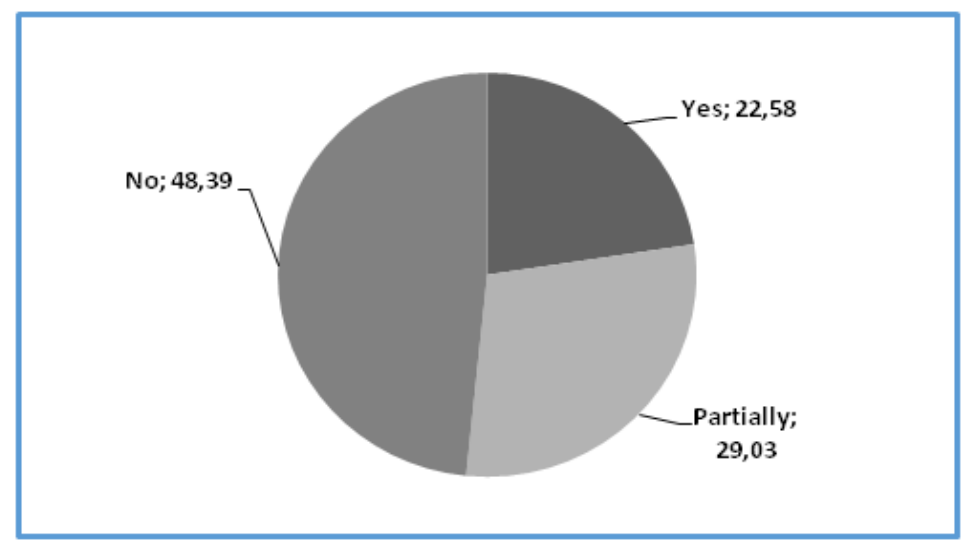

Fig. 2. Percentages of responses concerning the negotiation of different representations of learners

\subsection{Step 3: Mediation between learner and knowledge}

Question 3 (Q3) concerning teacher mediation between learner and knowledge shows that none of the future teachers interviewed chose the right answer, i.e. that the 
trainee could not be a good mediator between learner and knowledge (see Figure 3). While $51.61 \%$ of them stated that the teacher could be a good mediator between the learner and knowledge and $48.39 \%$ stated that they were partially able to be good mediators between the learner and knowledge.

We note that these results are worrying because it seems that not all future teachers have detected the right answers.

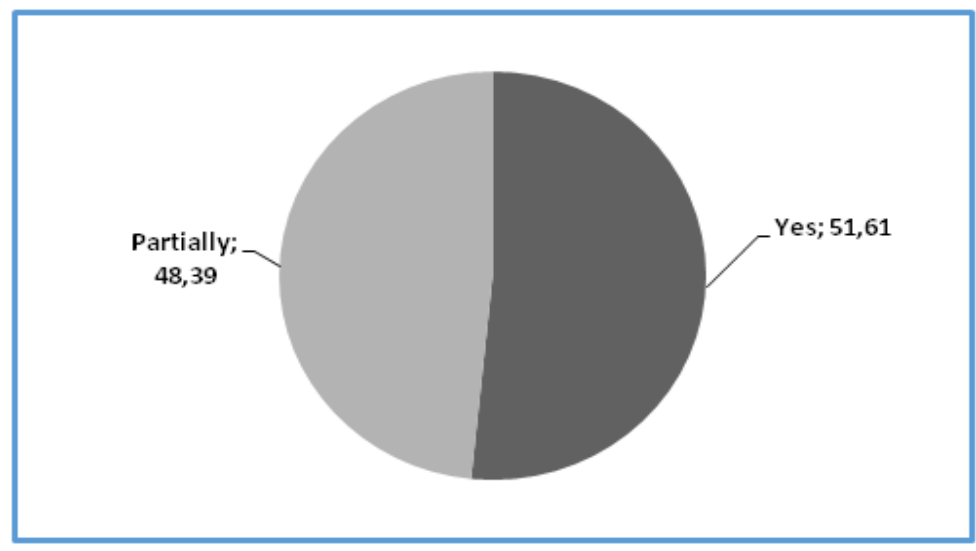

Fig. 3. Percentage of responses concerning mediation between learner and knowledge

\subsection{Step 4: Start the session with an exploration situation}

For question $4(\mathrm{Q} 4)$, which concerns the beginning of the session with an exploration situation (see Figure 4). The analysis of the responses of the future teachers showed that $61.29 \%$ of the teacher trainees opted for the correct proposal, namely that the trainee does not start the session with an exploration situation. As for the $22.58 \%$ of future teachers, they felt that they started the session with an exploratory situation, and $16.13 \%$ stated that they partially started the session with an exploratory situation.

It should be noted that nearly $2 / 3$ of the future teachers $(61.29 \%)$ answered correctly; these future teachers therefore detected this teaching practice, namely the beginning of the session with an exploratory situation. The others who almost $1 / 3$ chose incorrect answers. 


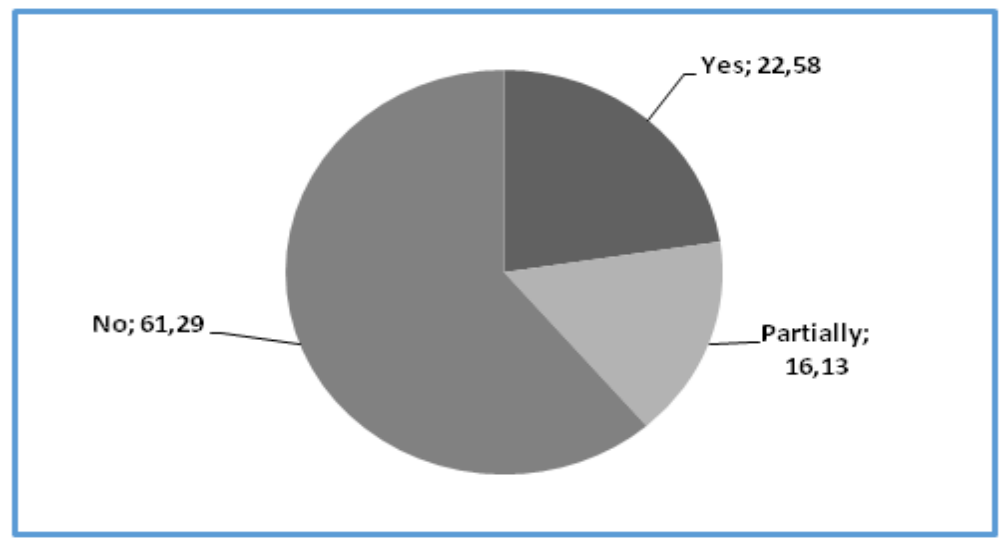

Fig. 4. Percentages of responses relative to the beginning of the session with an exploration situation

\subsection{Step 5: Manage space and time in a balanced way}

In question $5(\mathrm{Q} 5)$, which concerns the management of space and time in a balanced way. The analysis of the results obtained (see figure 5) shows that $45.16 \%$ of the future teachers questioned answered correctly, i.e. the trainee did not manage space and time in a balanced way, $29.03 \%$ of them say they managed space and time in a balanced way and $25.81 \%$ say they partially managed space and time in a balanced way.

We note that nearly half of the future teachers $(45.16 \%)$ chose the right answer and have the capacity to perceive such a teaching practice, which is the balanced management of space and time.

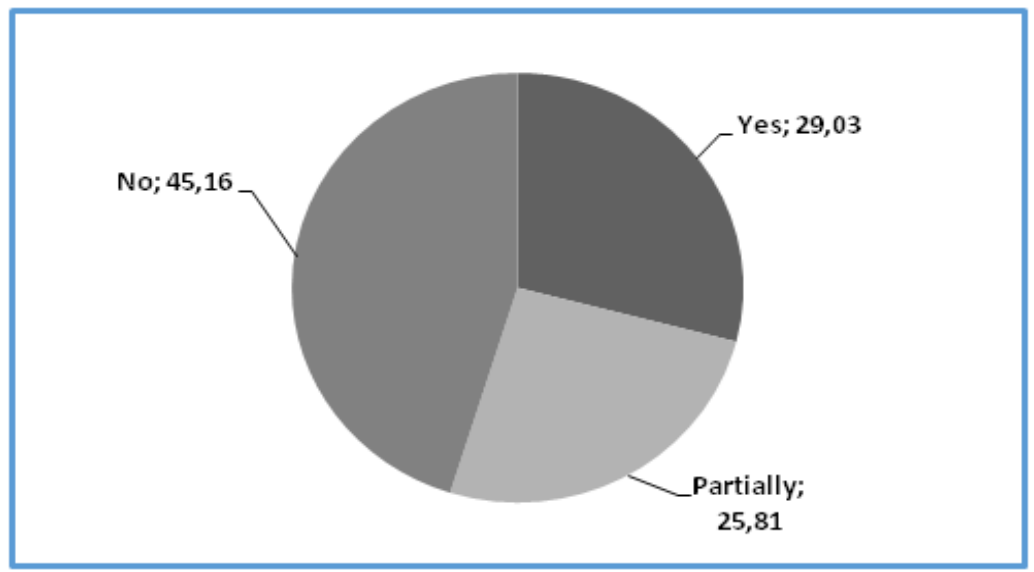

Fig. 5. Percentage of responses related to space and time management. 


\subsection{Step 6: Management of the interaction between teacher and students and between students themselves}

Question 6 (Q6) concerns the management of the interaction between the future teacher and his/her learners and the interaction between these learners (see Figure 6). The results show that $19.35 \%$ of the future teachers opted for the correct proposition, i.e. that the trainee has poorly managed the interaction between the teacher and learners and between these learners, $22.58 \%$ of them consider that they are able to manage the interaction between the teacher and learners and between these learners and $58.06 \%$ declare that they are partially able to manage the interaction between the teacher and learners and between these learners. It seems that only $19.35 \%$ of the teachers in training for qualification opted for the right answer and therefore acquired adequate knowledge to identify this teaching practice, namely the management of interaction with students and between students.

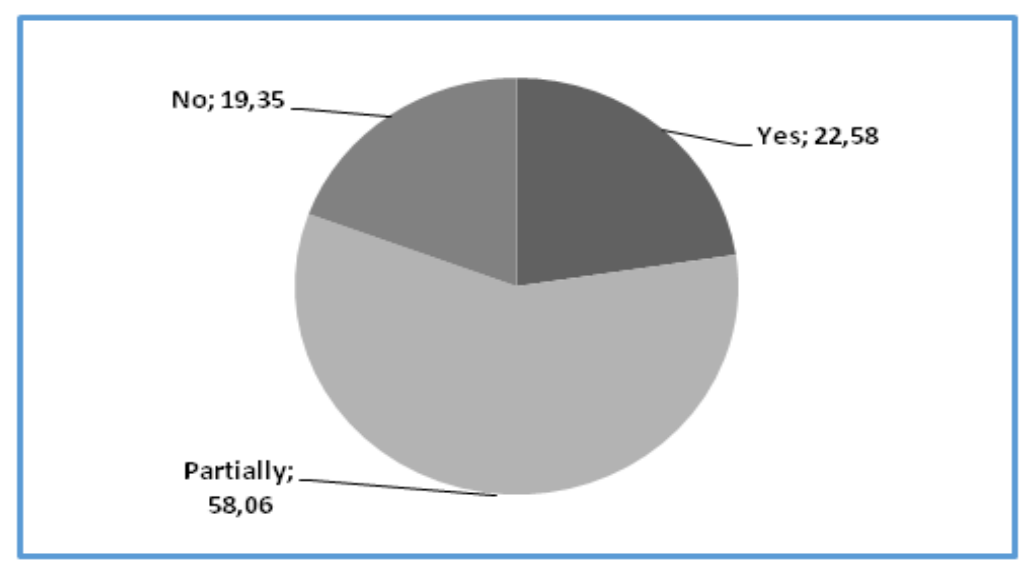

Fig. 6. Percentage of Responses Related to Managing Interaction with and Between Students

\section{Discussion}

In this part we will discuss the results obtained from the indicators or questions of the analysis grid, as follows:

The analysis of the results of future teachers, obtained from the first question (Q1): checking and correcting learners' errors shows that only $6.45 \%$ of future teachers questioned opted for the correct answer, that is to say that the trainee did not control and rectify the errors of the learners in an adequate way, on the other hand the rest, who constitute the majority, opted for the incorrect answers and therefore they did not acquire the knowledge necessary to identify this teaching practice since the trainee did not give too much importance to the self-correction of the learners and to the correction by the other students and in most cases, it is the teacher who corrects the errors of these learners, this is indeed consistent with a study conducted by Bucheton, D. in 
2009 [7]; about a gesture of synchronic piloting is under the close control of the future teacher who has the red pen in hand, checks, evaluates by right or wrong, he corrects himself the errors of the learners.

As for questions $(\mathrm{Q} 2)$ and $(\mathrm{Q} 3)$ : the second question $2(\mathrm{Q} 2)$ is based on the negotiation of the different representations of learners, the results show that $48.39 \%$ of the population having carried out the analysis opted for the correct proposition, that is to say that the trainee did not negotiate the different representations of the learners, the rest who is almost half of the interviewed population opted for the incorrect answer. As for question $3(\mathrm{Q} 3)$ which concerns the teacher's mediation between the learner and knowledge, the results are worrying because it seems that not all future teachers have detected the correct answer.

Thus, according to Bucheton, D. in 2009 [7], the fact of negotiating the different representations of learners and of being a mediator between the learner and knowledge, are supporting gestures that express the interest we need to support the learner in his journey. we notice that during the course of the lesson, the teacher is obliged to adjust and reorganize all of his concerns: taking time to come back to a notion, focusing attention on a problematic element of the knowledge and to negotiate the representations of the learners, this negotiation requires the mediation of the teacher between the learner and knowledge, which promotes the negotiation of a cognitive conflict. This mediation's point of view is consistent with the learning pedagogies which highlight the concept of cognitive conflict and emphasize the mediating role of the teacher in the resolution of this type of conflict [22]. The teacher, when he is a mediator, adjusts his possible choice of strategy to the evolution of the situation, depending on the students' responses and the problem raised, he follows the student in his thoughts by asking questions leading to take into account the elements relevant to the construction of his knowledge. As a result, we note the inability of the majority of future teachers to detect this mediation and the negotiation of representations, despite the fact that the trainee did not apply the mediation procedures and negotiation of representations.

The data obtained for question (Q4), which focuses on the beginning of the session with an exploration situation, seems to show that, $61.29 \%$ of teachers in qualifying training opted for the exact proposition, namely that the trainee did not start the session with an exploration situation, as for the others almost $1 / 3$ of the population questioned did not choose the correct answer. In fact, almost $2 / 3$ of future teachers detected the correct teaching practice, namely that the future teacher did not start the session with an exploratory situation to make the link between the sessions. Thus according to the study conducted by Bucheton, D. in 2009 [7], the task of highlighting the introduction is a weaving gesture that makes it possible to make links between the activities. It is the teacher's concern that leads him to articulate the different units of the lesson and the different sessions of the lesson to give consistency to the lessons.

For questions (Q5) and (Q6), the fifth question 5 (Q5) which concerns the management of space and time in a balanced way, the analysis shows that $45.16 \%$ of the future teachers questioned answered correctly, that is to say that the trainee did not manage time and space in an adequate way, the other future teachers who represent almost half of the questioned population opted for the incorrect answer. As for ques- 
tion 6 (Q6), which concerns the management of the interaction between learners and between the future teacher and his learners, the results show that only $19.35 \%$ of future teachers opted for the correct proposition, namely that the trainee mismanaged the interaction between learners and between the teacher and his learners. While almost $4 / 5$ have opted for the incorrect proposition and in fact these future teachers do not have the capacity to perceive such a class practice, namely the management of the interaction between learners and between the future teacher and his learners.

The results of (Q5) show that almost half of the future teachers (45.16\%) opted for the correct answer and thus, they have the ability to estimate such a teaching practice managing space and time in a balanced way. Indeed, the trainee did not pilot and organize the progress of the lesson, because this piloting is an action, which regulates time and space in a relevant way to maintain a good working atmosphere. Thus according to a study carried out by Bucheton, D. in 2009 [7], the management of time and space is the black beast of the future teacher, it is for him a constant concern to manage in parallel the various constraints relating to time: the succession of the tasks planned, the program, the evaluations and also to manage the space and material constraints: the possibilities offered by the table layout, the educational or technological equipment available. For the question (Q6) which concerns the management of interaction with students and between these students. The results show that $4 / 5$ of future teachers opted for the incorrect proposition. Thus, the maintenance of a certain atmosphere passes by the management of the feedbacks of the students; in fact the teacher is in charge of the maintenance of a cognitive and relational climate, of a philosophy which allows the singularity of the speech of the student and the individualization of learning, thus maintaining an adequate and relevant learning atmosphere is a difficult thing to achieve, hence the inability of the majority of future teachers to detect such teaching practice.

Finally, in response to research questions, it seems that the training model applied to the CRMEF, which is based on the professionalization of the profession of future teachers, does not make it possible to provide future teachers with the means and tools to develop and carry out their teaching practices on a daily basis; therefore, future teacher will not be trained in a way to be able to retrain and to be in constant questioning about his teaching practices and his professional act.

\section{Conclusion}

In conclusion, the implementation of a qualifying training implies the improvement of the professional gestures and pedagogical practices of future teachers. The analysis of classroom practices aims to see whether future teachers have acquired the knowledge necessary for these pedagogical practices and to detect their capacity to master and analyze them adequately. Nevertheless, it is difficult to implement this analysis of classroom practices because the teaching profession is complex, it is made up of singular situations where the teacher cannot master everything; it is a human profession with disciplinary motivation and didactic, pedagogical and interpersonal skills. As a result, we find that a number of trainees have developed the capacity to 
analyze these teaching practices, but the majority of them have not acquired this capacity. This incapacity is due to the difficulty of identifying certain gestures, in particular gestures that support the work in progress, control spatio-temporal dimensions, maintain a certain learning atmosphere and weave links between sessions and between lessons. This incapacity is also due to the virtual absence of alternation between training centers and educational institutions. Indeed, the four weeks spent in internships in host institutions during the training year are not sufficient to meet the needs of future teachers. According to Bucheton, D. in 2009 [7], among future teachers, identifying the learning object is difficult, because all the teaching objects are intertwined with each other.

Consequently, the qualifying training at the CRMEF must be reviewed, because in this training, the importance is given to pedagogical practices, with $60 \%$ of the hourly envelope being devoted to practical training and $40 \%$ to theory, therefore almost $2 / 3$ of the hourly mass is devoted to practice and the remaining $1 / 3$ to theory.

However, this training is in fact spread over only about six months, with about $20 \%$ of the hourly mass being spent on practical training and $80 \%$ on theory, so that this training is based more on theory than on practice. This situation will unfortunately have a negative impact on the teaching practices and training of trainees and, consequently, on the application and implementation of the new reform.

\section{$7 \quad$ Recommendations}

As a recommendation, the training of teachers in reflective practices is the highest level of training that exists, in this context we need a well-designed grid to analyze teaching practices adequately; unfortunately, there is a lack or even absence of analysis grids. This is why we are currently working on a broader analysis grid, composed of 20 indicators.

\section{Acknowledgement}

We would like to thank the future teachers who participated in the development of this work; we also thank all those who contributed directly or indirectly to this study.

\section{References}

[1] Moudouma E., Ginestie J., Armand H. (2011). Teaching practices and professional reality: cases of technical and industrial high school teachers in Gabon. Review of Science Mathemat-ics and ICT Education, Vol 5, No 1, 41-62. https://doi.org/10. 26220/rev.88

[2] Visioli J., Petiot O. (2017). The emotional dynamics of expert teachers during EPS: what is the relationship with availability to students? ejournal of research on intervention in physical education and sport, Vol 40, 31-63. Retrieved from http://elliadd.univfcomte.fr/ejrieps/system/files/eJR40_Visioli_et_Petiot.pdf.https://doi.org/10.4000/ejrieps.2 $\underline{008}$ 
[3] Lenoir Y. (2010). The reform of teacher training in Quebec. International review of education in Sèvres, Vol 55, 37-48. https://doi.org/10.4000/ries.930

[4] Riahi S., Riahi A. (2018). The Pedagogy of Higher Education: How to Evaluate the Quality of Training in Morocco to Improve it. International Journal of Engineering Pedagogy (iJEP) - Vol. 8, No. 1. https://doi.org/10.3991/ijep.v8i1.7984

[5] Trottier C. (2005). The analysis of the relations between the educational system and the world of work in the sociology of education: towards a recomposition of the field of study? Education and societies, Vol 16, No 2, 77-97. https://doi.org/10.3917/es.016.0077

[6] Uwamariya A., Mukamurera J. (2005). The concept of professional development in teaching: theoretical approaches. Journal of Educational Sciences, Vol 31, No 1, 133-155. https://www.erudit.org/fr/revues/rse/2005-v31-n1-rse994/012361ar/

[7] Bucheton D. (2009). Acting as a teacher: adjusted professional gestures. Journal of Educational Sciences, 37(3), 465-663. https://doi.org/10.7202/1014766ar

[8] Morel F., Bucheton D., Carayon B., Faucanié H., Laux S. (2015). Describe the professional gestures to understand efficient practices. French today, Vol 188, No 1, 65-77. https://doi.org/10.3917/lfa.188.0065

[9] Jorro A. (2016). Professional postures and gestures of trainers in the professional support of primary school teachers. ejournal of research on intervention in physical education and sport, Vol 38, 114-132. https://doi.org/10.4000/ejrieps.906

[10] Bucheton D., Soulé Y. (2009). Professional gestures and the play of the teacher's postures in the classroom: a multi-agenda of embedded concerns. Education and didactics, Vol. 3, No. 3, 29-48. https://doi.org/10.4000/educationdidactique.543

[11] Pastré P., Mayen P., Vergnaud G. (2006). Professional didactics. French Journal of Pedagogy, Vol 154, 145-198. https://doi.org/10.4000/rfp.157

[12] Casalfiore S. (2002). The structuring of the daily activity of teachers in class: towards an analysis in terms of situated action. French Journal of Pedagogy, Vol 138, 75-84. https://doi.org/10.3406/rfp.2002.2865

[13] Sensevy G., Mercier A. (2007). Acting together: the joint didactic action of the teacher and the students. French Journal of Pedagogy, Vol 160, 174-177. https://doi.org/10.4000/ $\underline{\text { rfp. } 906}$

[14] Altet M. (2017). Observation of effective teaching practices in the classroom. Cadernos de Pesquisa, Vol. 47, No. 166, 1196-1223. https://doi.org/10.1590/198053144321

[15] Leblanc S., Sève C. (2012). Video training and construction of professional experience. Re-search and training, Vol 70, 47-60. http://doi.org/10.4000/rechercheformation.1842

[16] Arwa Y. (2019). A Roadmap to the Development of Key Competencies of Engineering and Technology Graduates. International Journal of Engineering Pedagogy (iJEP) - Vol. 9, No. 5. https://doi.org/10.3991/ijep.v9i5.11094

[17] Meyer F. (2012). The example videos of how to bring about change. International Journal of Higher Education Pedagogy, Vol 28, No 2, 1-24. https://doi.org/10.4000/ripes.660

[18] Edward J., Berger J. F., Rhoads J. (2020). DeBoer, Student, Perspectives on the Learning Resources in an Active, Blended and Collaborative (ABC) Pedagogical Environment. Inter-national Journal of Engineering Pedagogy (iJEP) - Vol. 10, No. 2. https://doi.org/10.3991/ijep.v10i2.11606

[19] Jacques S., Ouahabi A., Lequeu T. (2020). Remote Knowledge Acquisition and Assessment During the COVID-19 Pandemic. International Journal of Engineering Pedagogy (iJEP) - Vol. 10, No. 6 https://doi.org/10.3991/ijep.v10i6.16205

[20] Mili A. (2014). Modeling grid of teaching practices during the management of learning situa-tions. ScienceLib, Vol 6, 1-13. 
[21] Bocquillon M., Derobertmasure A., Dehon A. (2017). The "Mirror of Professional Gestures" (MGP) grid, a tool for analyzing classroom practices: Working papers de l'INAS.

[22] Altet M. (2000). Analysis of practices: a professional training approach. Research and train-ing, Vol. 35, 25-41.

\section{Authors}

Abdelali Arbia is a trainer in the Life and Earth Sciences Department at the Regional Center for Education and Training for Professions (CRMEF) in Fez, Morocco. Email: arbiaabdelali@gmail.com

Ihsane Kouchou is an assistant professor in science didactics at the Normal High School (ENS), laboratory (LIRDEF), Cadi Ayyad University, Marrakech, Morocco. Email: Kouchouihsane88@gmail.com

Fatiha Kaddari is Professor of Higher Education; holder of a $\mathrm{PhD}$ in Analytical Chemistry from the University of Montpellier II; holder of a State Doctorate in Science Education from the University of Sidi Mohamed Ben Abdellah; director of several theses and author of about fifty articles. Email: kaddari@yahoo.fr

Rida Hajji Hour is a doctor of biology. Email: Rida.hajji@yahoo.fr

Abdelrhani Elachqar is vice-president in charge of academic and pedagogical affairs at the Sidi Mohamed Ben Abdellah University of Fez; teacher and researcher in the field of chemistry and science education, pedagogical innovation, ICT and evaluation; member of various committees for the implementation and evaluation of educational reform; author of several scientific articles in chemistry and educational sciences. Email: aelachqar@yahoo.fr

Article submitted 2020-12-13. Resubmitted 2021-02-12. Final acceptance 2021-02-21. Final version published as submitted by the authors. 